\title{
Relações entre a Filosofia e a Educação de John Dewey e de Paulo Freire
}

\author{
Darcísio Natal Muraro' \\ 'Universidade Estadual de Londrina (UEL), Londrina/PR - Brasil
}

RESUMO - Relações entre a Filosofia e a Educação de John Dewey e de Paulo Freire. O objetivo deste artigo é investigar a concepção de democracia e educação desenvolvida por John Dewey e Paulo Freire. Leitor da obra de Dewey, Freire teve contato também com o debate das ideias deste pensador no Brasil, sobretudo através dos trabalhos de A. Teixeira e L. Filho. Estudar como o pensamento deweyano ecoa na obra freireana ajuda a compreender a sua maneira original de tecer seus conceitos. Freire leva adiante a ideia deweyana de democracia como forma de vida guiada pelo pensamento reflexivo. Ele viu no diálogo problematizador e gerador dos sentidos da ação transformadora da situação social e histórica um processo educacional que pode conscientizar, humanizar, libertar e, assim, superar a opressão que também é historicamente criada pelo próprio homem.

Palavras-chave: Dewey. Freire. Democracia. Educação. Pensamento.

ABSTRACT - The Relationship Between the Philosophy and the Education of John Dewey and Paulo Freire. The aim of this paper is to investigate the concept of democracy and education developed by John Dewey and Paulo Freire. Reader of the work of Dewey, Freire also had contact with the debate of the ideas of this thinker in Brazil, particularly through the work of A. Teixeira and L. Filho. Study how the thought of Dewey echoes in Freire's work helps to understand his original way of weaving his concepts. Freire takes forward the idea of Deweyan democracy as a way of life guided by reflective thinking. He saw in the the problem-solving dialogue and generator of the meanings of the transforming action of the social and historical situation an educational process that can educate, humanize, free and, thus, overcome the oppression that is also historically created by man himself.

Keywords: Dewey. Freire. Democracy. Education. Thinking.

Educação \& Realidade, Porto Alegre, v. 38, n. 3, p. 813-829, jul./set. 2013.

Disponível em: <http://www.ufrgs.br/edu_realidade> 
Relações entre a Filosofia e a Educação de John Dewey e de Paulo Freire

O presente trabalho tem como foco investigar as possíveis relações entre as concepções de democracia e educação desenvolvidas por John Dewey e Paulo Freire. Investigar essas relações conceituais se traduz num esforço de leitura comparativa da produção teórica desses pensadores buscando responder à seguinte indagação: quais são as concepções deweyanas sobre democracia e educação aportadas na obra de Freire e de que forma são feitas?

Paulo Freire teve contato com o pensamento filosófico-educacional de Dewey tanto através da leitura das principais obras desse autor como através dos intelectuais que marcaram o debate educacional no Brasil, sobretudo a partir da década de 30 do século passado, destacando-se Anísio Teixeira, que foi um tradutor das obras de Dewey, e Lourenço Filho que foi um comentador do mesmo autor. Devemos considerar que as traduções e publicações de algumas obras de Dewey no Brasil, sobretudo as ligadas à educação, ocorreram nas décadas de 1930 a 1970. Outro fato significativo influenciado pelas ideias deweyanas é o surgimento do movimento educacional escolanovista que marcou o debate educacional-político nacional com dois importantes manifestos: Manifesto dos Pioneiros da Educação Nova (1932) e Manifesto dos Educadores (1959). Buscamos argumentar que o pensamento deweyano ecoa direta ou indiretamente na obra freireana, constituindo-se num campo de pesquisa anunciado, mas pouco explorado na tentativa de compreender como a leitura de Dewey contribuiu para a originalidade da criação da tessitura conceitual de Freire sobre democracia e educação.

Essas relações conceituais são anunciadas por diversos estudiosos da obra de Freire. McLaren e Silva, no artigo Descentralizando a Pedagogia afirmam: "Seguindo a tradição de Hegel, Marx e Dewey, Freire enfatiza a intencionalidade individual e coletiva ou agência como precondição para saber" (McLaren; Silva, 1998, p. 41, grifo nosso). Em sua obra Utopias Provisórias, McLaren declara que, dentre uma variedade de pensadores, a obra clássica de Dewey contribuiu para Freire desenvolver suas concepções:

Influenciada pela obra de Lucien Febvre, pela nouvelle pédagogie francesa de Célestin Freinet e Edouard Claparéde, pelos escritos de Leszek Kolakowski, Karel Kosik, Erich Fromm, Antonio Gramsci, Karl Mannheim, Teilhard de Chardin, Franz Fanon, Albert Memmi, Jean Piaget, Amílcar Cabral e pela Teoria do personalismo cristão de Tristão de Ataíde e Emanuel Mounier (sem falar na obra clássica de Hegel, Marx, Rousseau e Dewey), a pedagogia de Freire é antiautoritária, dialógica e interativa, colocando o poder nas mãos de estudantes e trabalhadores (McLaren, 1999, p. 25, grifo nosso).

Biesiegel, na obra de sua autoria intitulada Política e Educação Popular, faz um estudo do primeiro livro escrito por Freire. Segundo essa análise de Biesiegel, Freire estudou Dewey para desenvolver seu livro, tanto diretamente quanto indiretamente, nesse caso, através de Anísio:

814 Educação \& Realidade, Porto Alegre, v. 38, n. 3, p. 813-829, jul./set. 2013 Disponível em: <http://www.ufrgs.br/edu_realidade> 
O acurado estudo desses autores e, direta e indiretamente, neste caso via Anísio Teixeira, também o contato com as ideias de John Dewey, de certo modo vinculavam em larga medida esse primeiro livro de Paulo Freire a uma sólida tradição intelectual, de inspiração preponderantemente anglo-saxônica, voltada para a defesa da democracia como forma de vida e para a investigação dos melhores caminhos de sua realização na sociedade moderna (Beisiegel, 1992, p. 76, grifos nossos).

No estudo que busca compreender as fases do pensamento de Freire intitulado A Progressão do Pensamento Político-Pedagógico de Paulo Freire, Scocuglia reconhece haver raízes nas concepções deweyanas:

Traduzindo: a educação e a pedagogia não deixaram de realizar-se via diálogo, não deixaram de priorizar o ato de conhecimento, a busca da consciência crítica. Mas, o que antes era predominantemente psico-pedagógico, passou a ser prioritariamente político-pedagógico. Isso sem anular as preocupações psico-sociais que embasam suas propostas desde seus primeiros escritos de base escolanovista popular [principalmente relativa às ideias de Dewey/ Anísio Teixeira] (Scocuglia, 2001, p. 342, grifo do autor).

Passaremos ao estudo das relações entre democracia e educação através da análise comparativa das principais obras de Freire e Dewey. Adotaremos este procedimento devido à escassez de trabalhos nessa área. Iniciando por uma breve contextualização dos autores e da pesquisa.

Paulo Freire nasceu em Recife no dia 19 de setembro de 1921. Nessa data, John Dewey, com 62 anos de idade, estava fazendo conferências nas universidades chinesas de Pequim e Nanking a convite de seus alunos de doutorado da Columbia University. Nessa ocasião, Dewey acompanhou o movimento dos estudantes chineses pela democratização de seu país e apoiou o movimento feminista na defesa do direito das mulheres de serem admitidas nas escolas em mesmo nível de igualdade dos homens.

No ano de 1959, Paulo Freire publicou seu primeiro livro intitulado Educação e Atualidade Brasileira, no qual faz referência à obra Democracia e Educação de Dewey. Freire cita, nas referências dessa sua obra, diversos autores que têm influência da filosofia deweyana. Nesse mesmo ano, Dewey foi homenageado internacionalmente pelo centenário de seu nascimento. Na celebração dessa data, Anísio Teixeira (1959) coloca Dewey como um precursor de uma filosofia que explicitamente se coloca o problema da organização da sociedade democrática, com uma filosofia adequada, em face dos novos conhecimentos científicos, as novas teorias do conhecimento, da natureza, do humano e do social. Ele termina seu artigo indicando que essa tarefa exige atitude prática de se tornar "[...] autenticamente nacionais e tomarmos plena consciência de nossa experiência” (Teixeira, 1959, p. 27) para elaborarmos uma mentalidade brasileira e com ela a nossa filosofia e a nossa educação. 
Relações entre a Filosofia e a Educação de John Dewey e de Paulo Freire

Paulo Freire declarou que Anísio Teixeira era para ele um mestre. Entendemos que Freire levou adiante a tarefa propugnada por seu mestre de uma forma muito original buscando afinar as concepções deweyanas com a gravidade das condições históricas, sociais e educacionais do Brasil. Neste seu primeiro livro, Freire recorre com frequência às obras deste seu mestre. Retiramos um excerto para exemplificar a importância que Freire dá ao trabalho que Anísio Teixeira vinha desenvolvendo como educador, pensador e cientista social. Nessa citação, Freire se refere especialmente à crítica de Teixeira à educação elitista brasileira da época que era obstáculo à democratização:

\begin{abstract}
A uma sociedade que se democratiza, insistimos em oferecer, não uma educação com que 'visássemos à formação de todos os brasileiros para os diversos níveis de ocupação de uma democracia moderna, mas tão-somente à seleção de um mandarino das letras, da ciências e das técnicas' (Teixeira, 1957, p. 48-49, apud Freire, 2001, p. 12), afirma um dos mais lúcidos educadores brasileiros atuais, o professor Anísio Teixeira, em quem o educador se harmoniza com o pensador e o cientista social (Freire, 2002, p. 12).
\end{abstract}

Em 1964, Freire é obrigado a se exilar do país perseguido pelo governo dos militares, abortando o desenvolvimento de seu projeto de educação reflexiva, dialógica e democrática com bases epistêmicas e políticas contestadoras de toda forma de autoritarismo, especialmente a ditadura. Exilado no exterior (Chile, Estados Unidos e Suíça) até 1979, Freire continuou aprofundando suas concepções marcadas sua experiência que estava sendo alimentada pela leitura de mundo que ele fazia com o seguinte foco: “[...] minha terra é dor, fome, miséria, esperança também de milhões, igualmente famintos de justiça. [...] Quando penso nela, vejo o quanto temos que caminhar, lutando, para ultrapassar estruturas perversas de espoliação” (Freire, 2000b, p. 26).

Em seus escritos, conferências, entrevistas, aulas e conversas Paulo Freire se recusou a classificar seu pensamento sob a égide de uma referência teórica exclusiva. São muitas as tentativas de interpretar suas ideias sob as rubricas de humanista, marxista, dialético, dialógico, híbrido, educação popular, pedagogia crítica ou mesmo como inclassificável. É possível encontrar alguns desses conceitos em sua obra, mas seu pensamento não se esgota nesse ou naquele enquadramento teórico. $\mathrm{O}$ próprio autor alertou para os artifícios enganosos da educação tradicional ou do autoritarismo que se serve da sloganização, da propaganda, da manipulação (cf. Freire, 1980, p. 42-43). Procurou ser plural, dialogou com diferentes tendências de pensamento, buscou a diferença, rompeu fronteiras sem perder a consistência e a unidade na relação teoria e prática. Amou profundamente o país, a liberdade, a democracia e a educação como fonte de humanização. Assumiu o risco e a responsabilidade de pensar e agir pela transformação da realidade a partir de uma experiência de vida bem definida: a defesa de uma educação dialógica, problematizadora, crítica e democrática que potencializa a luta políti-

816 Educação \& Realidade, Porto Alegre, v. 38, n. 3, p. 813-829, jul./set. 2013 Disponível em: <http://www.ufrgs.br/edu_realidade> 
ca da classe trabalhadora pela transformação do sistema capitalista de exploração e alienação. O espírito vivo de sua obra convida à leitura, à problematização e ao diálogo, colocando, como o autor dizia, os slogans como problemas.

A continuidade desse trabalho nos põe diante do problema do ato de ler. A leitura tem eco. Ler é dar a si mesmo possibilidade e o prazer de ouvir o eco das ideias em nossa mente. Ler é pensar o pensamento pensado e se permitir ouvir o pensamento ainda não pensado. Alguns ecos podem ser amplificados, outros emudecidos, outros sequer podem ser ouvidos. Dewey ecoa na obra de Freire, mas nem sempre essa ressonância é ouvida. O que soa diferente quase sempre é tido como um ruído desagradável e, por isso, é dispensado ou afinado por outra sonoridade mais aquiescente. Muitas vezes a leitura é somente um ressoar das palavras do próprio leitor. Nosso esforço aqui é o de ouvir atentamente a repercussão do eco deweyano no bojo da obra freireana, até para poder experimentar outros ritmos e não ter de dançar sempre com a mesma música...

Buscamos ouvir este eco onde ele se encontra mais nítido: uma breve citação paradigmática feita por Freire na obra Educação como Prática da Liberdade que corrobora com a tese que ele estudou a obra de Dewey chamada Democracia e Educação. Reproduzimos a citação: “[...] a originalidade não está no fantástico, mas no novo uso de coisas conhecidas" (Dewey, 1979b apud Freire, 1989, p. 122). A reverberação dessas palavras em nossa mente suscita a seguinte indagação: Quais concepções deweyanas encontramos na obra de Freire? Que novo uso Freire faz das concepções deweyanas? O trabalho de rastrear detalhadamente as concepções deweyanas aportadas na obra de Freire exige um trabalho de pesquisa criterioso e extenso. Por isso, optamos por concentrar nossa reflexão nesse trabalho sobre as relações entre democracia e educação.

Contextualizar essa citação na obra de Dewey é um trabalho necessário para investigar a questão que nos propomos. Dewey se dedica a discutir o problema da democracia nos capítulos 6 e 7 da obra Democracia e Educação. A referida citação encontra-se no capítulo 12, cujo título é O Ato de Pensar e a Educação (1979b, p. 167). Dewey mostrou com clareza que a vida democrática depende de uma educação que desenvolva o hábito do pensamento reflexivo sobre os problemas da experiência. $\mathrm{O}$ pensar reflexivo é, para Dewey, condição de possibilidade da vida democrática. Freire condiciona a sua concepção de democracia ao exame dos problemas comuns como veremos. Procuraremos analisar a seguir a seguinte questão que está vinculada à democracia: como Dewey concebeu o pensamento reflexivo? Haveria uma interessante questão que deixamos para analisar em outra ocasião: há relações entre essa concepção de pensamento reflexivo e o método elaborado por Freire para a alfabetização? Retornemos à leitura do referido capítulo do livro Democracia e Educação do qual Freire retira a citação mencionada. Neste 
Relações entre a Filosofia e a Educação de John Dewey e de Paulo Freire

capítulo, o autor faz uma discussão sobre a primeira etapa do processo reflexivo que é a localização do ato de pensar na experiência, inicialmente indeterminada (confusa e duvidosa) e a segunda que é a decisão de querer interpretar os dados da situação para definir o problema, tendo-se uma situação problemática. Para superar, o método de tentativa e erro e tornar o ato de pensar numa experiência autenticamente reflexiva são necessários dois movimentos nesta etapa: examinar os dados oriundos da observação atenta da situação que origina o ato de pensar para retirar dela os dados relevantes e, por outro lado, buscar as informações, conhecimentos, conteúdos acumulados em experiências anteriores do sujeito ou da cultura. Esses dois movimentos articulados permitem localizar e definir a situação e o problema. Na etapa seguinte, a reflexão continua com a elaboração de hipóteses e suas consequências como soluções possíveis para o problema. A conclusão do processo reflexivo consiste na elaboração de um plano de ação para por à prova a hipótese (verificação). Para esse autor, o pensar reflexivo permite dar um salto no desconhecido a partir do que é conhecido pelo processo da inferência, da interpretação, da suposição, da observação cuidadosa. Ele diz: “[...] um pensamento (o que uma coisa sugere, e não a coisa tal como se apresenta) é criador, é uma incursão no novo. Ele subentende alguma inventividade" (Dewey, 1979b, p. 174). O novo, familiar de alguma forma, é visto sob nova luz, sob diferente uso dado ao mesmo na situação problemática. A novidade que o pensamento produz consiste na percepção de novas relações para as coisas familiares enriquecendo a experiência. Praticamente todos os conhecimentos - as descobertas científicas, invenções, teorias e as produções da arte - resultam deste processo. Nesse contexto do capítulo se insere a referida citação do texto de Dewey feita por Freire que, na forma original, encontra-se da seguinte maneira:

Só as pessoas tolas identificam a originalidade com o extraordinário e o fantasioso; as outras reconhecem que a mesma consiste em dar às coisas conhecidas usos que ainda não haviam ocorrido a outras pessoas. É nova a operação, mas não são novos os materiais com que aquela é feita. A conclusão pedagógica a tirar-se disto é que todo o ato de pensar é original quando faz surgir considerações que ainda não tinham sido anteriormente apreendidas (Dewey, 1979b, p. 174-175).

Na concepção deweyana, o pensar reflexivo se desenvolve a partir do problema originário da experiência de vida. A investigação reflexiva é uma operação necessariamente original na medida em que leva a reconstruir as crenças e solucionar a situação problemática, produzindo, assim, o conhecimento: "[...] é infinito esse processo em espiral: matéria desconhecida a transformar-se, pelo pensamento, em possessão familiar; possessão familiar a instituir-se em recursos para julgar e assimilar outra matéria desconhecida" (Dewey, 1979a, p. 285-286). 
Na obra Como Pensamos, Dewey desenvolve o papel da reflexão para aquisição de conhecimentos, condição necessária para desenvolver a consciência de novos problemas. Vejamos como ele trata dessa questão no seguinte excerto:

\begin{abstract}
Refletimos para poder conseguir plena e adequada compreensão do que ocorre. Todavia, cumpre que alguma coisa já esteja compreendida, que o espírito já tenha dominado alguma significação, pois de outra maneira seria impossível pensar. O aumento de cabedal de significados nos torna conscientes de novos problemas; mas só traduzindo as novas perplexidades em termos do que nos é familiar e patente é que as compreenderemos e resolveremos. Esse é o contínuo movimento em espiral do conhecimento. Progredir verdadeiramente no saber consiste sempre, em parte, na descoberta de alguma coisa, não compreendida no conjunto previamente tido como patente, óbvio, natural; e, em parte, no emprego dos significados diretamente apreendidos, como instrumentos de domínio dos significados obscuros e duvidosos (Dewey, 1979a, p. 142, grifos do autor).
\end{abstract}

Para esse autor a educação é uma experiência reflexiva contínua regida pelo pensamento inquiridor: “[...] pensar é inquirir, investigar, examinar, provar, sondar para descobrir alguma coisa nova ou ver o que já é conhecido sob prisma diverso. Enfim, é perguntar" (Dewey, 1979a, p. 262, grifo do autor).

Se pensar é o método de educar é porque tem a finalidade de transformar a realidade, iniciando, desenvolvendo e ampliando a órbita de significados da experiência humana. Decorre daí sua definição de educação: “[...] é uma reconstrução ou reorganização da experiência, que esclarece e aumenta o sentido desta, e também, a nossa aptidão para dirigir o curso das experiências subsequentes" (Dewey, 1979a, p. 83, grifos do autor).

Dessa exposição podemos extrair algumas conclusões: primeira, a experiência de vida é o campo empírico de origem e destino do pensamento; segunda, o ato de pensar implica originalidade ao transformar a situação; terceira, aprender a pensar os problemas da experiência é a principal função da educação e é condição de possibilidade para a vida democrática; quarta, a vida democrática não é repetição de modelos, fórmulas, de uma pauta de protocolos definitivos ou aplicação mecânica de conhecimentos memorizados, mas contínua reconstrução da experiência compartilhada na qual a experiência acumulada (conteúdos) são imprescindíveis. Vamos aprofundar essas ideias estabelecendo relações com a obra de Freire.

Essa maneira de conceber o pensar reflexivo por Dewey ecoa na noção freireana do ciclo gnoseológico: “[...] ensinar, aprender, pesquisar lidam com esses dois momentos do ciclo gnoseológico: o que se ensina e se aprende o conhecimento existente e o em que se trabalha a produção

Educação \& Realidade, Porto Alegre, v. 38, n. 3, p. 813-829, jul./set. 2013.

Disponível em: <http://www.ufrgs.br/edu_realidade> 
Relações entre a Filosofia e a Educação de John Dewey e de Paulo Freire

do conhecimento ainda não existente" (Freire, 2000a, p. 31). É importante salientar que Freire define a educação como uma "[...] situação gnoseológica” (Freire, 1980, p. 90). Freire faz a relação entre educação e o ciclo gnoseológico para mostrar o potencial de libertação que a educação carrega. Esta mesma ideia, Freire utiliza ao expor sua concepção de homem como um ser que conhece, um ser em permanente processo de busca que faz e refaz seu saber: "[...] e é por isto que todo saber novo se gera num saber que passou a ser velho, o qual, anteriormente, gerando-se num outro saber que também se tornara velho, se havia instalado como saber novo" (Freire, 1980, p. 47).

Freire recria a concepção de problema ou problematização utilizando como diapasão a experiência do sujeito histórico e social no Brasil. No caso da educação, diz ele, essa postura fica muito clara: “[...] ninguém, na verdade problematiza algo a alguém e permanece, ao mesmo tempo, como mero expectador da problematização. [...] A problematização não é sublinhemo-lo uma vez mais um entretenimento intelectualista, alienado e alienante; uma fuga da ação; um modo de disfarçar a negação do real" (Freire, 1980, p. 82).

Nesse sentido, Freire utiliza a expressão situações-limites (1998, p. 91) que constitui o "[...] contorno ecológico, social e econômico em que vivemos" (Freire, 2000a, p. 155) como campo temático a ser problematizado: “[...] o próprio dos homens é estar, como consciência de si e do mundo, em relação de enfrentamento com sua realidade em que, historicamente, se dão as "situações-limites" (Freire, 1998, p. 91). Somente com o enfrentamento destas situações transformando a realidade é possível a libertação e a humanização, criando o domínio da cultura e da história. Freire define o homem como “[...] ser de práxis" (Freire, 1998, p. 92) e entende este termo da seguinte forma: "[...] práxis que, sendo reflexão e ação verdadeiramente transformadora da realidade, é fonte de conhecimento reflexivo e criação" (Freire, 1998, p. 92). Se a ideia de práxis de Freire é tomada pela tonalidade do pensamento marxista, marcante nas últimas décadas do século passado, pode-se dizer também que representa uma mixagem com as concepções deweyanas de pensamento reflexivo.

Dewey estabelece um ponto central em sua teoria educacional como contraposição à educação tradicional: o estudo, o aprendizado através da experiência reflexiva é descoberta e não armazenamento de conhecimentos de experiências alheias. Despejar conhecimentos na mente da criança, como se houvesse um aprendizado de ideias diretamente, é trabalho perdido: “[...] nenhum pensamento ou ideia pode ser transferido como ideia de uma pessoa para outra” (Dewey, 1979b, p. 175). Isto porque, explica Dewey, a ideia que é dita constitui um fato para quem ouve, e não ideia. Esta ideia não é algo vital, a não ser como uma lição ou uma exigência para passar num exame: “[...] a comunicação pode servir de estímulo para a outra pessoa compreender a questão e conceber uma ideia semelhante, ou pode abafar seu interesse intelec- 
tual e aniquilar seu incipiente esforço para pensar" (Dewey, 1979b, p. 175).

Os próprios alunos tomam estas supostas ideias como conhecimentos inúteis e inertes. Dewey levanta duas consequências nefastas para a vida do estudante:

[...] a experiência ordinária dos estudantes não adquire o enriquecimento que poderia ter; não é fecundada pelos estudos escolares. E as atitudes advindas de acostumarem-se a isso e de absorver material semicompreendido e semidigerido, enfraquecem o vigor e a eficiência mentais (Dewey, 1979b, p. 177).

Em outra passagem aparece explicitamente a crítica de Dewey sobre a educação como verbalismo ou comunicados:

Saber de segunda mão, saber que não é nosso, mas dos outros, tende a tornar-se meramente verbal. Nada se objeta a que as informações sejam expressas com palavras; a comunicação opera-se necessariamente por meio de palavras. Mas na proporção em que o comunicado não possa ser incorporado à experiência existente de quem aprende, converteu-se em simples palavras isto é, estímulos sensoriais desprovidos de significação (Dewey, 1979b, p. 207, grifos do autor).

Essa educação serve mais para escravizar "[...] o professor, ou o compêndio, que atulha os alunos com noções que, com pouco mais de trabalho, eles próprios poderiam descobrir por investigação direta, ofende-lhes a integridade intelectual, leva-os a cultivar a servidão mental" (Dewey, 1979a, p. 254). A servidão mental é incompatível com a vida democrática.

A crítica deweyana à educação tradicional ecoa profundamente na obra de Freire, especialmente na crítica que este faz à educação bancária como extensão dos saberes, comunicados e neste sentido é silenciadora e domesticadora contrapondo-se à educação progressista (cf. Freire, 1980, 1989, 1998, 2000). Assim, para Freire, a educação tradicional serve à adaptação do aluno à ordem existente, e uma consciência domesticada, alienada, tem sido um grande empecilho ao desenvolvimento da vida democrática.

Para Dewey, a posse de uma ideia vem na medida em que a pessoa trabalha reflexivamente com um problema que se torna uma causa vital, e que lhe cobra uma resposta numa experiência comum ou conjunta. Os pais e professores podem oferecer condições que estimulem o pensamento e cooperem com a experiência conjunta, mas não podem assumir e resolver o problema pelo outro. Somente nesta condição haverá aprendizado. O contraponto do transmitir ideias preparadas ou feitas é o fazer com que o aprendiz "[...] participe de situações significativas onde a sua própria atividade origina, reforça e prova as ideias - isto é, significações ou relações percebidas" (Dewey, 1979b, p. 176). Nesse contexto, Dewey explicita sua maneira de ver a ação do docente:

Educação \& Realidade, Porto Alegre, v. 38, n. 3, p. 813-829, jul./set. 2013.

Disponível em: <http://www.ufrgs.br/edu_realidade> 
Isto não quer dizer que o docente fique de lado, como simples expectador, pois o oposto de fornecer ideias já feitas e matéria já preparada, e de ouvir se o aluno reproduz exatamente o ensinado, não é inércia e sim a participação na atividade. Em tal atividade compartida, o professor é um aluno e o aluno é, sem o saber, um professor - e, tudo bem considerado, melhor será que, tanto o que dá como o que recebe a instrução tenha menos consciência possível de seu papel (Dewey, 1979b, p. 176, grifos nossos).

Freire criou a seguinte fórmula: “[...] ninguém educa ninguém, ninguém educa a si mesmo, os homens se educam entre si, mediatizados pelo mundo" (Freire, 1998, p. 68). Aos nossos ouvidos, essas expressões soam muito próximas, ou seja, a atividade compartida é mundo da experiência onde os homens se educam entre si. Na educação problematizadora, continua Freire:

[...] o educador já não é mais o que apenas educa, mas o que enquanto educa, é educado, em diálogo com o educando que ao ser educado, também educa. Ambos, assim, se tornam sujeitos do processo em que crescem juntos e em que os argumentos de autoridade já não valem. Em que, para ser-se, funcionalmente, autoridade, se necessita de estar sendo com as liberdades e não contra elas (Freire, 1998, p. 68, grifos do autor).

Para ambos, o decisivo no processo de conhecer é a relação com o problema. Vejamos agora a posição de Freire: “[...] ninguém, na verdade problematiza algo a alguém e permanece, ao mesmo tempo, como mero expectador da problematização. [...] A problematização não é sublinhemo-lo uma vez mais um entretenimento intelectualista, alienado e alienante; uma fuga da ação; um modo de disfarçar a negação do real" (Freire, 1980, p. 82).

Para Dewey a condução da solução dos problemas pressupõe a mediação do diálogo como condição de uma educação democrática. Defende aqui a prática da discussão - troca de ideias, experiências entre os componentes da classe - como o mais fidedigno pré-requisito. Ele começa por colocar o contexto dessa prática e também a necessidade da autoridade do professor: “[...] deveria ser uma situação em que uma classe, um grupo organizado como unidade social de interesses comuns, dirigido por pessoa mais madura e experimentada, favorecesse o ardor mental" (Dewey, 1979a, p. 260).

Para Dewey, a discussão deve tratar de problemas vitais para os alunos e não colocados artificialmente pelo professor. Neste caso, a ação do professor de levantar os problemas subjacentes, ou seja, os problemas conceituais para pensar a situação, define o foco da discussão. Diz sobre a maneira de o professor encaminhar a discussão:

[...] a discussão deveria ser encaminhada de maneira que concentrasse o pensamento em uns poucos pontos essenciais, ao redor dos quais se organizassem outras conside- 
rações. Assim conduzida, a discussão induzirá o estudante a evocar e reexaminar o que aprendeu em suas experiências pessoais anteriores e o que aprendeu de outros (isto é, levá-lo-á a refletir) a fim de descobrir o que se relaciona, positiva ou negativamente, com o assunto do momento. Embora não se deva permitir que a discussão degenere em bate-boca, uma discussão ardorosa mostrará as diferenças intelectuais, os pontos de vista e interpretações opostas, o que contribuirá para definir a verdadeira natureza do problema (Dewey, 1979a, p. 261, grifo do autor).

Freire (1998, p. 78-79) defende o diálogo como “[...] encontro amoroso dos homens, mediatizados pelo mundo, para pronunciá-lo" (grifo do autor) assim, modificando e transformando e criando a significação do humano. Ele contesta práticas de conversação que descaracterizam o diálogo: “[...] não é também discussão grosseira, polêmica, entre sujeitos que não aspiram a comprometer-se com a pronúncia do mundo, nem a buscar a verdade, mas a impor a sua" (Freire, 1998, p. 79, grifo do autor). É forte a crítica de Freire à educação verbalista em consonância a crítica deweyana como expusemos acima:

[...] todo que fazer educativo, portanto, [...] que se limite a dissertar, narrar, a falar de algo, em vez de desafiar a reflexão cognoscitiva dos educandos em torno de algo, além de neutralizar aquela capacidade cognoscitiva, fica na periferia dos problemas. Sua ação tende à ingenuidade e não à conscientização dos educandos (Freire, 1980, p. 86).

Freire retoma o potencial democrático do diálogo na obra Pedagogia da Esperança. Ele argumenta essa relação da seguinte forma: "Enquanto relação democrática, o diálogo é a possibilidade de que disponho de, abrindo-me ao pensar dos outros, não fenecer no isolamento" (Freire, 2011, p. 166). Neste sentido, o diálogo tem potencial transformador no campo da educação enquanto potencializa uma prática democrática. A prática do educador progressista ancorada no diálogo pode ser democrática em relação aos conteúdos sem esperar que a sociedade global se democratize (cf. Freire, 2011). A democracia não surge de uma prática autoritária. Vejamos o argumento de Freire:

O diálogo entre professoras ou professores e alunos ou alunas não os torna iguais, mas marca a posição democrática entre eles ou elas. Os professores não são iguais aos alunos por $n$ razões, entre elas porque a diferença ente eles os faz ser como estão sendo. Se fossem iguais, um se converteria no outro. O diálogo tem significação precisamente porque os sujeitos dialógicos não apenas conservam a sua identidade, mas a defendem e mesmo crescem um com o outro. O diálogo, por isso mesmo, não nivela, não reduz um ao outro. Nem é favor que um faz ao outro. Nem é tática manhosa, envolvente, que usa para confundir o outro. Implica ao contrário, um respeito fundamental dos sujeitos nele engajados que o autoritarismo rompe

Educação \& Realidade, Porto Alegre, v. 38, n. 3, p. 813-829, jul./set. 2013. 
Relações entre a Filosofia e a Educação de John Dewey e de Paulo Freire

ou não permite que se constitua. Assim também a licenciosidade, de forma diferente, mas igualmente prejudicial (Freire, 2011, p. 162-163, grifos do autor).

O desenvolvimento da capacidade de se comunicar e resolver os problemas sociais, com a participação ativa e livre na vida democrática, é uma das tarefas da educação. A vida democrática necessita de uma educação que capacite as pessoas a solucionar problemas com uso do instrumento da inteligência e da cooperação, e não na memorização de conteúdos ou verdades fixas. Daí a inseparabilidade da democracia da educação e ambas do pensar a experiência problemática. Entramos, assim, no problema da democracia para os autores que, a nosso ver, tem profunda consonância no sentido de ser uma forma de vida em transformação regida pelo pensar como maneira de lidar com os problemas comuns por meio do diálogo e da comunicação.

Freire pensou o conceito de democracia da seguinte forma:

\begin{abstract}
A democracia que, antes de ser forma política, é forma de vida, se caracteriza, sobretudo por forte dose de transitividade de consciência no comportamento do homem. Transitividade que não nasce e nem se desenvolve a não ser dentro de certas condições em que o homem seja lançado ao debate, ao exame de seus problemas e dos problemas comuns. Em que o homem participe (Freire, 1989, p. 80).
\end{abstract}

Dewey o pensou de maneira semelhante: “[...] uma democracia é mais do que uma forma de governo; é, essencialmente, uma forma de vida associada, de experiência conjunta e mutuamente comunicada" (Dewey, 1979, p. 93). Democracia é a discussão pública inteligente em torno de problemas comuns. O voto como instrumento político é um efeito. Por si só este não produz democracia. A sociedade democrática está baseada na comunicação, cooperação e livre interação entre todos os indivíduos envolvidos nos problemas e não no uso da força para solucionar os conflitos. Democracia deve ser praticada da base ao topo da sociedade e não o inverso.

A similaridade do soar desses conceitos de democracia como forma de vida pautada pelo diálogo, pela comunicação em torno dos problemas comuns levanta também uma aparente dissonância no uso que Freire faz dos termos consciência e transitividade. No nosso entender, a expressão forte dose de transitividade de consciência no comportamento do homem mostra o sentido deweyano de experiência reflexiva. Freire traduz a ideia de experiência regida pelos princípios de interação e continuidade de Dewey no conceito de conscientização crítica como fundamento da democracia. Os termos consciência e transitividade são recorrentes na obra de Dewey e guardam indissociável relação com a solução de problemas comuns. Para exemplificar, vejamos o seguinte excerto: “[...] a experiência presente da criança não se explica por si mesma, justamente porque não é final, mas de transição; porque não é 
uma coisa completa, mas simplesmente indicativa de certas tendências vitais de crescimento" (Dewey, 1959, p. 48, grifo nosso).

Freire coloca o problema da experiência democrática no Brasil e constata que ela é inexistente em nossa história: família patriarcal, escola tradicional, religião dogmática, política opressora, economia excludente, sindicatos pelegos, sociedade como grande divisão de classes, trabalho semiescravo. Diante desse quadro, a sua esperançosa aposta é a libertação pela educação conscientizadora como condição de possibilidade para uma vida democrática. Como alçar este salto democrático diante da inexperiência democrática como já apontavam Fernando de Azevedo e Anísio Teixeira? Citando-os, Freire coloca o problema da seguinte forma: “[...] a nossa cultura fixada na palavra corresponde a nossa inexperiência do diálogo, da investigação, da pesquisa, que, por sua vez, estão intimamente ligados à criticidade, nota fundamental da mentalidade democrática" (Freire, 1989, p. 96). Ele acredita no papel da educação para esta transformação:

\begin{abstract}
De uma educação que tentasse a passagem da transitividade ingênua à transitividade crítica, somente como poderíamos, ampliando e alargando a capacidade de captar os desafios do tempo, colocar o homem brasileiro em condições de resistir aos poderes da emocionalidade da própria transição. Armá-lo contra a força do irracionalismo, de que era presa fácil, na emersão que fazia, em posição de transitividade ingênua (Freire, 1989, p. 86).
\end{abstract}

Nessa perspectiva, educação na e para a democracia buscando a “[...] emersão do povo na vida pública” exige uma mudança de postura: "[...] de uma educação que levasse o homem a uma nova postura diante dos problemas de seu tempo e de seu espaço" (Freire, 1989, p. 93). E ainda: "[...] realmente instrumental, porque integrada ao nosso tempo e ao nosso espaço e levando o homem a refletir sobre sua ontológica vocação de ser sujeito" (Freire, 1989, p. 106). Nessa linha de raciocínio a educação e os círculos de cultura têm função de criar a forma democrática de viver: "[...] assim, iríamos ajudando o homem brasileiro, no clima cultural da fase de transição, a aprender democracia, com a própria existência desta" (Freire, 1989, p. 86). Freire está convicto de que a construção da democracia não se dá à custódia, mas é um processo de luta ética e política condição de possibilidade para a humanização do ser humano: “[...] não se recebe a democracia de presente. Luta-se pela democracia. Não se rompem as amarras que nos proíbem de ser como uma paciência bem comportada, mas com povo mobilizando-se, organizando-se, conscientemente crítico" (Freire, 2000b, p. 117). Daí a necessidade de uma educação conscientizadora e um movimento social como esforço de libertação, e não como instrumento de adaptação ou dominação. É oportuno retomar aqui outra definição de educação elaborada por Freire (1980, p. 77): “[...] é comunicação, é diálogo, é um encontro de sujeitos interlocutores que procuram a significação dos significados”. O salto

Educação \& Realidade, Porto Alegre, v. 38, n. 3, p. 813-829, jul./set. 2013.

Disponível em: <http://www.ufrgs.br/edu_realidade> 
Relações entre a Filosofia e a Educação de John Dewey e de Paulo Freire

previsto por Freire é que a democracia como forma de vida depende da educação para se transformar em democracia também como forma de governo.

Para Dewey, o problema dado historicamente era o de pensar a continuidade e ampliação da vida social democrática que depende do esforço voluntário. Consideremos que, embora a experiência de vida de Dewey se desenvolveu num contexto democrático (família, religião, escola, universidades, governo) que se insere numa tradição americana de defesa da democracia que vem pelo menos desde T. Jefferson, ele declara que o caminho da democracia não é um caminho fácil. Por isso, a defesa que faz de uma educação voltada para desenvolver os hábitos e atitudes democráticos. Desta forma, a democracia e a educação constituem o equilíbrio da balança da vida social. Uma educação deliberada e sistemática é mais condizente com a comunhão democrática em que os interesses se interpenetram e se regulam mutuamente proporcionando progresso ou readaptações. Uma sociedade democrática somente será eficiente se a vida associada dos concidadãos for uma experiência onde os significados são construídos e comunicados numa ação conjunta de livre comunicação e participação. Repudiando a autoridade externa, política e intelectual, governantes, líderes e cidadãos regulam suas ações a partir dos critérios da democracia. Daí ser a democracia um princípio que, como forma de vida, deve afetar completamente o ser humano:

A ideia de democracia é mais ampla e mais completa do que suas possíveis aplicações nos mais felizes dos casos. Para ser realizada, ela deve afetar todos os modos de associação humana: família, escola, indústria, religião. E mesmo no que tange a arranjos políticos, as instituições governamentais são apenas um mecanismo de fixar numa ideia canais de operação efetiva (Dewey, 1991, p. 148).

Por isso, a democracia é um ideal amplo e aberto em permanente reconstrução. A sociedade democrática é a única capaz de permitir a livre e necessária comunicação da experiência entre os indivíduos proporcionando a continuidade e interação da vida social. No âmbito social, a interação exige associação e cooperação comunitária, ações mediadas pela comunicação com os outros membros da espécie. Para Dewey, a sobrevivência humana significa sobrevivência social que se realiza através da reflexão, ação e comunicação.

A própria inteligência tem origem na cooperação social, conforme pensa Dewey: “[...] inteligência é um bem, um ativo social que se reveste de função tão pública quanto é, concretamente, sua origem na cooperação social" (Dewey, 1970, p. 77). A inteligência é o instrumento socializador por excelência e adequado para atuar com eficácia no sentido de restabelecer a continuidade da experiência.

A democracia tem significado moral e ideal como confirma Dewey: “[...] temos de ver que democracia significa a crença de que deve 
prevalecer a cultura humanística; devemos ser francos e claros em nosso reconhecimento de que a proposição é uma proposição moral, como qualquer ideia referente a dever ser" (Dewey, 1970, p. 212, grifos do autor). Dewey identifica a causa da democracia com a moral:

\begin{abstract}
[...] a causa de democracia é a causa moral da dignidade e do valor do indivíduo. Através do respeito mútuo, da mútua tolerância, do dar e receber, da associação das experiências, ela é, enfim, o único método através do qual o ser humano pode ter sucesso em levar adiante este experimento no qual nós estamos todos engajados, queiramos ou não, o grande experimento da humanidade - o de viver juntos de modo que a vida de cada um de nós seja pelo menos vantajosa, no mais profundo sentido da palavra, vantajosa para si mesmo e que contribua para a construção da individualidade dos outros (Dewey, 1946, p. 33).
\end{abstract}

Esta crença tem sua base no princípio de que a inteligência é um bem, um ativo social que se origina na cooperação social e tem função pública:

[...] a democracia tem significação moral e ideal, é porque se exige de todos uma retribuição social e porque se proporciona, a todos, oportunidade para o desenvolvimento das suas aptidões distintivas. O divórcio dos dois objetivos na educação é fatal à democracia; a adoção da significação mais restrita de eficiência priva-a de sua justificação essencial (Dewey, 1979b, p. 133).

Decorre daí o valor da educação, pois é por meio dela que se pode proporcionar a todos a possibilidade de se aquinhoarem dos benefícios sociais e desenvolverem suas aptidões individuais, e exige, também, de todos a respectiva retribuição social. Para Dewey, a educação deve propiciar um ambiente favorável para que cada indivíduo tenha a possibilidade de desenvolver sua natureza potencialmente social. Da mesma forma, a reflexão da filosofia sobre as necessidades humanas na luta pela sobrevivência deve ser regida pelos fins e valores democráticos para a garantia dos mesmos. A filosofia deverá ser o corolário da democracia. Assim sendo, como processo da experiência tem valor educativo, a fé na democracia guarda íntima relação com a fé na experiência e na educação que se traduz num agir esperançoso da transformação da situação de conflito para uma situação inteligentemente resolvida, permitindo o crescimento individual e social.

Retomando nosso raciocínio, a educação é, para ambos, a transformação da própria vida, entendida por Dewey como ampliação das possibilidades de vida pela aquisição da capacidade de pensar reflexivamente os problemas e, por Freire, como desenvolvimento da consciência crítica que problematiza a própria realidade como condição de superação das condições históricas opressoras.

Para Dewey, a democracia não se encerra numa forma de governo, mas abrange a totalidade das relações humanas. Ela começa em casa,

Educação \& Realidade, Porto Alegre, v. 38, n. 3, p. 813-829, jul./set. 2013.

Disponível em: <http://www.ufrgs.br/edu_realidade> 
Relações entre a Filosofia e a Educação de John Dewey e de Paulo Freire

na vizinhança, no trabalho e se constitui numa forma de vida que é mutuamente comunicada, alimentada pela educação, e permanentemente reconstruída pela reflexão.

Tais concepções repercutem na obra de Freire entendendo a dimensão de comunicabilidade da experiência na democracia pela noção de transitividade da consciência que se dá pela participação e pela dialogicidade. Freire foi muito sensível em sua leitura identificando a precária experiência democrática, inclusive no âmbito da educação e pela luta que deveria se travar pela transitividade da consciência, ou conscientização, num processo educacional dialógico, problematizador, crítico, ético e político.

Educação é para ambos uma ação social, cultura e política da comunidade humana na direção da libertação, ou no termo empregado por ambos, uma educação progressiva. Freire percebeu que libertação exigia um trabalho de educação popular específico das massas diante da exploração econômica e política do país.

Haveria de se romper com a educação bancária, manipuladora, domesticadora, extensão dos saberes fixos das classes dominantes. A crítica de Dewey dirige-se à educação tradicional ou mesmo a educação que se diz renovada que impediam a transformação da experiência e colocavam a democracia em risco. Aliás, democracia é uma noção em construção que se sustenta num componente de fé ou de esperança. Assim, para Dewey, o professor é um servidor social que entende que a educação “[...] é a regulação do processo de chegar a participar da consciência social, e a adaptação da atividade individual sobre a base dessa consciência social é o único método seguro de reconstrução social" (Dewey, 1940, p. 15).

Freire defendeu teórica e praticamente uma educação como prática de liberdade, uma prática democrática, dialógica e reflexiva sobre os problemas concretos que afligem o povo brasileiro. Em termos práticos significa que os instrumentos para transformação social, política, educacional, religiosa são círculos de cultura, os movimentos sociais, uma escola voltada para o pensar (perguntar, problematizar) e para o diálogo, uma prática religiosa de comunidades de bases que forme a consciência crítica da classe trabalhadora.

Sabemos que todo esforço que fazemos não esgota a possibilidade de ouvir todos os ecos. A preocupação que nos guiou foi uma tentativa de possibilitar ouvir consonâncias e dissonâncias marcadas por intervalos de tempos entre os autores e seus leitores. A tarefa continua para quem quer se colocar numa experiência de abertura, experiência de vida, experiência democrática, experiência educativa que se dispõe a ouvir atentamente e procura pensar e dialogar como forma de apreender e de aprender.

Recebido em 26 de dezembro de 2011 Aprovado em 22 de maio de 2012

828 Educação \& Realidade, Porto Alegre, v. 38, n. 3, p. 813-829, jul./set. 2013 Disponível em: <http://www.ufrgs.br/edu_realidade> 


\section{Referências}

BEISIEGEL, Celso de Rui. Política e Educação Popular. (A Teoria e a Prática de Paulo Freire no Brasil). São Paulo: Ática, 1992.

DEWEY, John. Como Pensamos como se Relaciona o Pensamento Reflexivo com o Processo Educativo: uma reexposição. Tradução: Haydée Camargo Campos. 4. ed. São Paulo: Nacional, 1979a. Atualidades Pedagógicas, v. 2, 292 p.

DEWEY, John. Democracia e Educação. Tradução de Godofredo Rangel e Anísio Teixeira. São Paulo: Nacional, 1979b. Atualidades Pedagógicas, vol. 21

DEWEY, John. Education Today. Edited and with a foreword by Joseph Ratner. New York: G.P. Putnam's Sons, 1940. 373p.

DEWEY, John. Liberalismo, Liberdade e Cultura. Tradução de Anísio Teixeira. São Paulo: Nacional, 1970.

DEWEY, John. The Public and its Problems. 12. ed. Ohio: Ohio University Press, 1991.

DEWEY, John. Problems of Men. New York: Philosophical Library, 1946. 424p.

DEWEY, John. Vida e Educação. Tradução de Anísio Teixeira. 5. ed. São Paulo: Nacional. 1959

FREIRE, Paulo. Educação como Prática da Liberdade. 19. ed. Rio de Janeiro: Paz e Terra, 1989.

FREIRE, Paulo. Educação e atualidade brasileira. 2. ed. São Paulo: Cortez; Instituto Paulo Freire, 2002.

FREIRE, Paulo. Extensão ou Comunicação? 4. ed. Rio de Janeiro: Paz e Terra, 1980.

FREIRE, Paulo. Pedagogia do Oprimido. 25. ed. Rio de Janeiro: Paz e Terra, 1998. FREIRE, Paulo. Pedagogia da Autonomia, Saberes Necessários à Prática Educativa. São Paulo: Paz e Terra. 15. ed. 2000a.

FREIRE, Paulo. À Sombra desta Mangueira. 3a. ed. SP: Ed. Olho d’Água, 2000b. FREIRE, Paulo. Pedagogia da Esperança. São Paulo: Paz e Terra. 15. ed. 2011.

McLAREN, Peter. Utopias Provisórias. Petrópolis, Rio de Janeiro: Vozes, 1999.

McLAREN, Peter; SILVA, Tomaz Tadeu da. Descentralizando a Pedagogia. Alfabetização Crítica, Resistência e Política da Memória. In: MCLAREN, Peter; LEONARD, Peter; GADOTTI, Moacir (Org.). Freire: poder, desejo e memórias da libertação. Porto Alegre: ArtMed, 1998. P. 35-75.

SCOCUGLIA, Afonso Censo. A Progressão do Pensamento Político-Pedagógico de Paulo Freire. In: TORRES, Carlos Alberto (Org.). Paulo Freire y la Agenda de la Educación Latinoamerica en El siglo XXI. Buenos Aires: CLACSO, 2001. P. 323348.

TEIXEIRA, Anísio. Filosofia e Educação. Revista Brasileira de Estudos Pedagógicos, Rio de Janeiro, v. 32, n. 75, p. 14-27, jul./set. 1959.

Darcísio Natal Muraro é professor Adjunto da Universidade Estadual de Londrina, no CECA - Centro de Educação, Comunicação e Artes, Departamento de Educação, onde desenvolve atividades de ensino, pesquisa e extensão. Tem projeto de pesquisa na área de filosofia e educação. Atuou como professor nas seguintes Instituições: UFPR, PUCSP, PUCPR, PUCMG, UNIPAC, UP.

E-mail:dmuraro@uel.br

Educação \& Realidade, Porto Alegre, v. 38, n. 3, p. 813-829, jul./set. 2013. 